\title{
ANÁLISES ENERGÉTICAS DA PRODUÇÃO DE LEITE BOVINO EM ÁREA DE PROTEÇÃO AMBIENTAL: UM INDICADOR DE SUSTENTABILIDADE
}

\section{Marísia Cristina da Silva ${ }^{1}$}

\section{Osmar de Carvalho Bueno ${ }^{2}$}

RESUMO: A atividade agropecuária é a principal fonte de fornecimento de alimentos para a humanidade além de contribuir para o desenvolvimento local, regional, e até mesmo nacional. Atualmente, com a intensificação dos impactos ambientais em muitos municípios com vocação agropecuária, faz-se necessária a preocupação tanto com as transformações provindas destes impactos no meio ambiente, quanto com o estímulo ao desenvolvimento de um modelo mais sustentável de desenvolvimento para a zona rural. Muitos municípios, que apresentam tradicional vocação econômica voltada para a produção leiteira e inserida em uma Área de Proteção Ambiental, destacam também preocupações da sustentabilidade local. A finalidade do presente trabalho é apresentar a importância da análise energética em sistemas de produção de bovinos de leite, presentes na Área de Proteção Ambiental Corumbataí-Botucatu-Tejupá destacando a dependência dos agroecossistemas de energia externa e de fontes não renováveis, particularmente de fontes fósseis, como um indicador de sustentabilidade, proporcionando dessa maneira a utilização dos recursos não renováveis de forma mais consciente. Com essas análises, pode-se obter um indicador de sustentabilidade identificando assim a dependência energética de fontes não renováveis no agroecossistema e assim buscar alternativas produtivas que se baseiam nos conceitos de sustentabilidade.

Palavras-chave: Análises Energéticas. Sistemas de produção de leite. Indicador de sustentabilidade.

\footnotetext{
${ }^{1}$ Engenheira Agrônoma, Doutoranda em Agronomia pelo Programa de Pós-Graduação Energia na Agricultura - Faculdade de Ciências Agronômicas - UNESP. E-mail: mcsilva@fca.unesp.br.

2 Engenheiro Agrônomo, Faculdade de Ciências Agronômicas - UNESP. Professor Adjunto. E-mail: osmar@fca.unesp.br.
} 


\section{INTRODUÇÃO}

A atividade agropecuária é a principal fonte de fornecimento de alimentos para a humanidade além de contribuir para o desenvolvimento local, regional, e até mesmo nacional. Porém, quando não desenvolvida em bases social, econômica e ambientalmente sustentáveis, acarreta significativos impactos adversos ao meio ambiente.

A produção agropecuária que se realizou sob a ótica do desenvolvimento rural concebido como sinônimo de modernização acarretou graves problemas no contexto da sustentabilidade, uma vez que os agroecossistemas carregam um elevado grau de ineficiência energética e causam impactos ambientais como a erosão dos solos, a poluição das águas e dos solos por nitratos, fosfatos e agrotóxicos, a contaminação dos agricultores e dos alimentos, a destruição das florestas, a diminuição da biodiversidade e dos recursos genéticos e a destruição dos recursos não renováveis [MENEGETTI, 199-].

Coutinho (2002) afirma que esse modelo de desenvolvimento rural, caracterizado pela elevada utilização de agrotóxicos, não considerou os efeitos sob o meio ambiente e sobre as populações, provocando a contaminação e a degradação de solos e, por consequência, dos reservatórios de águas, a salinização, os desequilíbrios ecológicos e promovendo a perda da biodiversidade.

O desenvolvimento rural sustentável surge reconhecendo a "insustentabilidade" do modelo de desenvolvimento contemporâneo (SCHMITT, 1995).

Atualmente, com a intensificação dos impactos ambientais em muitos municípios com vocação agropecuária, faz-se necessária a preocupação tanto com as transformações provindas destes impactos no meio ambiente, quanto com o estímulo ao desenvolvimento de um modelo mais sustentável de desenvolvimento para a zona rural.

Destacando a produção brasileira de leite, esta vem crescendo a taxas ao redor de 5\% ao ano nos últimos anos e em 2010 produziu 30,7 bilhões de litros; mantendo a mesma taxa, as estimativas indicam que o volume nacional alcançara 32,2 bilhões de litros até o final de 2011 (ZOCCAL et al. 2011). 
De acordo com Martins (2003), o volume de produção de leite intensificou-se devido à forma diferenciada de pagamento do litro de leite ao produtor rural, associada à modernização da atividade.

Para que a atividade leiteira alcance índices de produção desejáveis, há necessidade de buscar a competitividade no mercado, com bases sustentáveis de produção.

Muitos municípios, que apresentam tradicional vocação econômica voltada para a produção leiteira e inserida em uma Área de Proteção Ambiental, destacam também preocupações da sustentabilidade local. São identificadas como produção de alimentos, geração de renda minimamente satisfatória, redução ao máximo da agressão ao meio ambiente, prática de manejo conservacionista dos solos agrícolas, planejamento agrícola em conformidade com a legislação ambiental, conservação dos recursos naturais, além de efetuar a gestão ambiental dos resíduos agrícolas; motivos estes que evidenciam a necessidade de estudos mais aprofundados para a busca do desenvolvimento sustentável para a região.

Diante da importância da influência do desenvolvimento rural na economia do país da pecuária leiteira para o estado de São Paulo e frente ao imperativo da gestão ambiental dos municípios que compõem uma Área de Proteção Ambiental, destaca-se a necessidade da busca de alternativas produtivas mais sustentáveis do ponto de vista energético e socioeconômico para os produtores de leite bovino da região.

A finalidade do presente trabalho é apresentar a importância da análise energética em sistemas de produção de bovinos de leite, presentes na Área de Proteção Ambiental Corumbataí-Botucatu-Tejupá destacando a dependência dos agroecossistemas de energia externa e de fontes não renováveis, particularmente de fontes fósseis, como um indicador de sustentabilidade, proporcionando dessa maneira a utilização dos recursos não renováveis de forma mais consciente. 


\section{A IMPORTÂNCIA DA PECUÁRIA DE LEITE PARA O ESTADO DE SÃO PAULO EM ÁREA DE PROTEÇÃO AMBIENTAL CORUMBATAÍ-BOTUCATU-TEJUPÁ}

O leite é tradicionalmente considerado um produto de origem animal de amplo consumo mundial. Além do mais, a produção leiteira é historicamente considerada uma das principais atividades econômicas da agropecuária e encontra-se estabelecida em todas as regiões brasileiras e sob os mais diversos formatos de estruturação e desenvolvimento.

De acordo com o Censo Agropecuário do IBGE (2011) indica que no Brasil existem aproximadamente 5,2 milhões de estabelecimentos rurais e em 25\% (1.350.809 milhões) deles trabalham com produção de leite.

Zoccal et al. (2011), afirmam que o maior percentual de propriedades com leite em relação ao número total de estabelecimentos rurais ocorre nas Regiões Sul $(41 \%)$ e no Centro-Oeste $(39 \%)$. No Norte $18 \%$ e no Nordeste apenas $16 \%$ deles se dedicam à atividade. Já no Sudeste $33 \%$ do total de estabelecimentos trabalham com leite.

No que se refere à produção de leite no país, de acordo com o IBGE (2011), no ano de 2010 a produção de leite de vaca chegou a 30,7 bilhões de litros, um acréscimo de $5,6 \%$ sobre o ano anterior. Foram ordenhadas 22,9 milhões de vacas em todo o país, representando $10,9 \%$ do efetivo total de bovinos. A maior produtividade de leite foi no Sul (2.388 litros/vaca/ano), com destaque para Santa Catarina (2.432 litros/vaca/ano). Minas Gerais foi responsável por 27,3\% da produção nacional de leite, Rio Grande do Sul por $11,8 \%$, e Paraná por $11,7 \%$. Entre os municípios produtores, destacou-se Castro (PR), o maior produtor nacional de leite (180,0 milhões de litros) e com produtividade média de 7.115 litros/vaca/ano.

De acordo com Ministério da Agricultura, Pecuária e Abastecimento - Assessoria de Gestão Estratégica (2011) a produção de leite deverá crescer a uma taxa anual de 1,9\%. Isso corresponde a uma produção de 38,2 bilhões de litros de leite cru em 2020/2021. O consumo deverá crescer a uma taxa praticamente igual a da produção. A taxa de crescimento da produção é superior à observada para o crescimento da população brasileira. 
De modo particular observa-se que na produção de leite, como em muitas das atividades agropecuárias, tem sido frequentemente utilizadas fontes energéticas de origem não renovável como, por exemplo, fertilizantes, herbicidas e o diesel (SILVEIRA, 2010).

Essa utilização tem por objetivo alcançar produção de leite em quantidade, bem como qualidade suficiente para manter altos índices de produtividades em seus rebanhos, assim gerando renda ao setor em âmbito nacional e regional.

Por outro lado, tem gerado problemas complexos relacionados não somente às questões ambientais como, também, sociais e econômicas.

Problemas ambientais, sociais e econômicos da atividade de produção leiteira, ensejam preocupações, com a questão da sustentabilidade da cadeia produtiva do setor leiteiro e suas inter-relações.

Neste sentido, a preocupação em desenvolver e implantar sistemas de produção sustentáveis, buscando o equilíbrio entre os pilares econômico, social, cultural e ambiental, vem ganhando importância nos cenários estadual, nacional e internacional.

Assim, é evidente a importância da pecuária de leite como atividade econômica no Brasil.

Vale ressaltar que a pecuária leiteira está presente em todo território brasileiro. Zoccal et al. (2007) apontam a presença da produção de leite em 554 microrregiões das 558 consideradas pelo Instituto Brasileiro de Geografia e Estatística (IBGE).

Porém, não há um padrão de produção de leite no Brasil, uma vez que há desde propriedades de subsistência, sem técnica de manejo e com produção diária inferior a 10 litros, até propriedades com técnicas avançadas de manejo e produção diária superior a 60.000 litros de leite.

Ao se comparar com a produção de leite nacional, verifica-se que o estado de São Paulo é um dos principais produtores, possuindo o quarto maior rebanho de pecuária leiteira do Brasil e situando-se dentre os quatro principais estados produtores de leite.

Todavia esse cenário, de acordo com Silva et al. (2003), vem sofrendo expressivas modificações, com a transformação de sua estrutura, bem como dos métodos operacionais, desde o final da década de 90 não somente no país como, em especial, no 


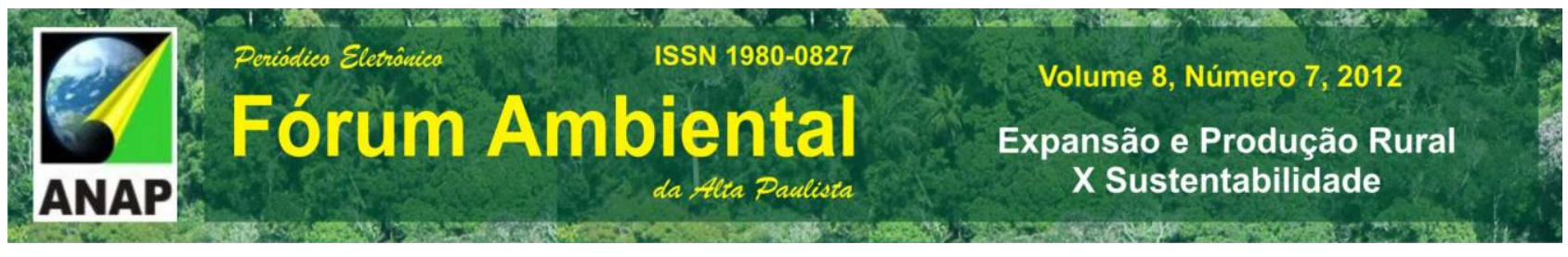

estado paulista. Assim, ocorreu o desenvolvimento de um ambiente competitivo no mercado de leite.

Destaca-se que o estado paulista, que apresenta em seu território a APA perímetro Botucatu, de acordo com o IEA (2009), no ano passado produziu 2.031.641 (1000 litros/ano) de leite, o que marca a forte presença da atividade, consequentemente com seus impactos ao meio ambiente.

A produção leiteira estadual ultrapassou em 2004 a marca de 2 bilhões de litros, propiciando um crescimento de 4,8\% em relação ao ano anterior. Este índice foi o maior registrado desde o início do século e representou aproximadamente $8 \%$ do volume de produção do leite produzido no Brasil (IEA, 2005).

De acordo com o IEA (2009), no ano de 2008 o Estado de São Paulo produziu 2.031.641 (1000 litros/ano) de leite.

Com respeito a esta produção, devem ser destacados os EDRs ${ }^{3}$ de Botucatu ${ }^{4}$,

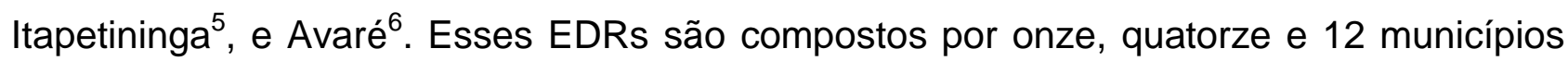
respectivamente e contribuíram para a produção de leite no estado de São Paulo com 41.487 milhões de litros/ano, 44.018 milhões de litros/ano e 29.578 milhões de litros/ano, de acordo com IBGE (2008).

Dos nove municípios que integram a APA Corumbataí-Botucatu-Tejupá, três compõem o EDR Botucatu, cinco o EDR de Itapetininga e um compõe o EDR de Avaré.

Dessa forma, dados os aspectos ambientais, sociais e ambientais apontados, percebe-se a importância de novas tecnológicas e a utilização de indicadores de sustentabilidade para que os impactos adversos provindos da atividade leiteira sejam reduzidos com o objetivo de preservar os recursos naturais inseridos em um agroecossistema.

3 A estrutura da Coordenadoria de Assistência Técnica Integral está apoiada 40 Escritórios de Desenvolvimento Rural (EDR's) distribuídos por todo 0 estado de São Paulo (fonte: http://www.cati.sp.gov.br/new/enderecos.php).

4 EDR de Botucatu: Anhembi - Areiópolis - Bofete - Botucatu - Conchas - Itatinga - Laranjal Paulista Pardinho - Pereiras - Pratânia - São Manuel.

${ }^{5}$ EDR de Itapetininga: Alambari - Angatuba - Campina do Monte Alegre - Capão Bonito - Cesário Lange Guareí - Itapetininga - Porangaba - Quadra - Ribeirão Grande - São Miguel Arcanjo - Sarapuí - Tatuí - Torre de Pedra.

${ }^{6}$ EDR de Avaré: Águas de Santa Bárbara - Arandu - Avaré - Barão de Antonina - Cerqueira César - Coronel Macedo - laras - Itaí - Itaporanga - Manduri - Paranapanema - Taquarituba. 


\section{3 ÁREA DE PROTEÇÃo AMBIENTAL CORUMBATAí-BOTUCATU-TEJUPÁ: PERÍMETRO BOTUCATU/SP}

A Área de Proteção Ambiental (APA) pode ser considerada como uma categoria de unidade de conservação relativamente nova, pois sua implementação deu-se na década de 80, com base na Lei Federal no 6.902, de 27 de abril de 1981. São apreciados como espaços para planejamento e gestão ambiental de áreas extensas que alocam ecossistemas de importância regional, reunindo um ou mais atributos ambientais. As APAs necessitam de ordenamento territorial orientado com o objetivo do uso sustentável dos recursos naturais, elaborado por meio de processos participativos da sociedade, resultando na melhoria da qualidade de vida das comunidades locais ${ }^{7}$.

A APA Corumbataí/Botucatu/Tejupá, foi criada durante a gestão 1983-1987 de Franco Montoro no governo do estado de São Paulo pelo Decreto Estadual o 20.960, de 8 de junho de 1983, Deliberação CONSEMA no 142 de 12/12/1986, Lei Estadual n. 7.438 de 06/07/1991 e Resolução SMA s/n de 11 de março de $1987^{8}$ e apresenta uma área total de $6.492 \mathrm{~km}^{2}$.

Dando destaque para o perímetro Botucatu, da referida APA, conhecido também como APA de Botucatu, foi criado com o objetivo de proteger os cenários paisagísticos, representados pelas Cuestas Basálticas e os Morros Testemunhos, os recursos hídricos superficiais, o Sistema Aquífero Guarani e o patrimônio arqueológico e os remanescentes de vegetação nativa, especialmente o cerrado.

A APA de Botucatu apresenta uma área de 218.306 hectares, resguardando a Serra de Botucatu e a formação denominada Cuestas Basálticas, entre os rios Tietê e Paranapanema, resultante do trabalho contínuo de erosão, que formou grandes plataformas rochosas que se destacam nos vales suaves ao seu redor.

Seu território se estende por aproximadamente $70 \%$ da área total dos municípios de Angatuba, Avaré, Bofete, Botucatu, Guareí, Itatinga, Pardinho, São Manuel e Torre de

7 Fonte: http://www.ambiente.sp.gov.br/apas/apa.htm

${ }^{8}$ Fonte: http://www.fflorestal.sp.gov.br/apasEstaduais.php 
Pedra, além de ser uma das zonas de recarga do manancial Aquífero Guarani que aflora nessa região ${ }^{9}$.

De acordo com Silva e Bueno (2011), a APA de Botucatu apresenta muitas preocupações de cunho ambiental e socioeconômico, bem como, tradicional vocação econômica voltada para a produção leiteira.

Em virtude do afloramento do Aquífero Guarani na região, a área da APA é uma das zonas de recarga desse importante e estratégico manancial subterrâneo e, em razão disso, o coloca em situação de grande vulnerabilidade ${ }^{10}$.

Este manancial subterrâneo, em particular no que concerne à região da APA de Botucatu, vem sendo utilizado para diversos fins, principalmente para a produção agropecuária e o abastecimento humano, muito embora sem contar com uma estrutura organizada para a gestão dos recursos hídricos do Sistema Aquífero Guarani (RIBEIRO, 2008).

\section{AGROECOSSISTEMA LEITEIRO E A DEPENDÊNCIA DE FONTES NÃO RENOVÁVEIS}

Sabe-se que fontes não renováveis, especificamente derivadas do petróleo são utilizadas na produção leiteira assim como na agropecuária em geral.

Nesse sentido, Campos (2001) ao realizar um estudo de análise energética relativo à produção de feno em bovinocultura de leite, constatou a necessidade de avaliação do agroecossistema em questão. Ao observar a criação dos animais, o autor considerou a energia envolvida em todas as etapas de produção, tais como: utilização de pastagens, de ensilagens e de fenos; os quais apresentam alta demanda em quantidade de energia para sua produção.

O autor ainda confirma que através da análise energética, foi possível constatar que os derivados de petróleo, foram os maiores consumidores de energia, sendo somente o óleo diesel responsável por $73,94 \%$ do consumo total, que engloba a energia direta e indireta.

De acordo com Costa (2010), que estudou a eficiência energética e econômica da produção de leite bovino, a disponibilidade futura dos recursos é de crescente

\footnotetext{
${ }^{9}$ Fonte: http://www.fflorestal.sp.gov.br/hotsites/hotsite/sobre.php

${ }^{10}$ Fonte: http://www.fflorestal.sp.gov.br/hotsites/hotsite/sobre.php
} 
preocupação, pois varia inversamente com o ritmo de exploração, logo, o ajustamento de recursos como esgotável, e muitas vezes não renováveis, pressupõe a possibilidade de uma escassez futura.

De acordo com Bueno (2002), a análise energética pode ser entendida como um processo de avaliação das "entradas" (inputs) e das "saídas" (outputs) de energia dos agroecossistemas.

Do ponto de vista da sustentabilidade, nos agroecossistemas, as fontes energéticas usadas podem ser limitantes. Podem ser renováveis ou não renováveis e podem ser poluidoras ou não poluidoras ao meio ambiente (BASSO, 2007).

Com a avaliação energética do agroecossistema leiteiro, pode-se verificar o nível de dependência desse sistema, bem como, as diferentes formas de energia, compreendendo-se melhor as necessárias adequações na condução da atividade em relação aos dispêndios energéticos (SILVEIRA, 2010).

Diante disso, percebe-se a necessidade de promover a análise energética em agroecossistemas de produção leiteira para identificação das fontes energéticas e assim dimensionar o impacto ambiental que essas fontes causam em um agroecossistema.

\section{CONCLUSÃO}

Fica evidente a importância da realização de análises energéticas em sistemas de produção de leite presentes na Área de Proteção Ambiental Crumbataí-Botucatu-Tejupá. Com essas análises, pode-se obter um indicador de sustentabilidade identificando assim a dependência energética de fontes não renováveis no agroecossistema e assim buscar alternativas produtivas que se baseiam nos conceitos de sustentabilidade, permitindo que o uso racional dos recursos não renováveis, que estão cada vez mais escassos na natureza, seja realizado conscientemente.

\section{REFERÊNCIAS}

BASSO, Z. F. C. Análise energética da produção de leite bovino em explorações familiares na região de Botucatu-SP. Botucatu, 2007. 108p. Dissertação (Mestrado em Agronomia/ Energia na Agricultura) - Faculdade de Ciências Agronômicas (FCA) Universidade Estadual Paulista (UNESP). 
BUENO, O. C. Análise energética e eficiência cultural do milho em assentamento rural, Itaberá/SP. Botucatu, 2002. 146p. Tese (Doutorado em Agronomia/ Energia na Agricultura) - Faculdade de Ciências Agronômicas (FCA) - Universidade Estadual Paulista (UNESP).

CAMPOS, A. T. Balanço energético relativo à produção de feno "coastcross" e alfafa em sistema intensivo de produção de leite. 2001. $236 \mathrm{f}$.

Tese (Doutorado em Agronomia/Energia na Agricultura) - Faculdade de Ciências Agronômicas (FCA), Universidade Estadual Paulista (UNESP). Botucatu. 2001.

COSTA, Z. DA F. Eficiência energética e econômica da produção de leite bovino em explorações familiares no município de Pardinho, região de Botucatu-SP. Botucatu, 2010. 132p. Tese (Doutorado em Agronomia/ Energia na Agricultura) - Faculdade de Ciências Agronômicas (FCA) - Universidade Estadual Paulista (UNESP).

COUTINHO, H. L. C. (2002) - Biodiversidade: perspectivas e oportunidades tecnológicas. CNPS/EMBRAPA. Seropédica, RJ. Disponível em:

<http://www.bdt.tat.org.br/publicacoes/padct/bio/cap9/1/heitoag.html>. Acesso em: 01 set. 2012.

IEA - INSTITUTO DE ECONOMIA AGRÍCOLA. Banco de Dados IEA, 2005. Disponível em <http://www.iea.sp.gov.br/out/ibcoiea.php>. Acesso em: 06 set. 2012.

IEA - INSTITUTO DE ECONOMIA AGRÍCOLA. Série Informações Estatísticas da Agricultura, 2009. Disponível em: <http://www.iea.sp.gov.br/out/anuario.php>. Acesso em: 07 set. 2012.

IBGE. Instituto Brasileiro de Geografia e Estatística. Produção pecuária. 2008. Disponível em: <http://www.ibge.gov.br/servidor_arquivos_est/>. Acesso em: 06 out. 2012.

IBGE. Instituto Brasileiro de Geografia e Estatística. Produção pecuária. PPM 2010: Rebanho bovino nacional cresce 2,1\% e chega a 209,5 milhões de cabeças. 2011. Disponível em: $<$ http://www.ibge.gov.br/home/presidencia/noticias/noticia visualiza.php?id noticia=2002\& id pagina=1>. Acesso em: 08 out. 2012.

IBGE. Instituto Brasileiro de Geografia e Estatística. Produção pecuária/Pesquisa da Pecuária Municipal e Censo Agropecuário. SIDRA. 2011. Disponível em: $<w w w . s i d r a . i b g e . g o v . b r>$. Acesso: 23 set. 2012.

MARTINS, Marcelo Costa. CENTRO NACIONAL DE PESQUISA DE GADO DE LEITE. Comissão Nacional de Pecuária de Leite. Agronegócio do Leite. Ano III, n. 13, Abril 2003, p.2. 
MENEGETTI,G. A. Desenvolvimento, sustentabilidade e agricultura familiar. Disponível em: <http://www.emater.tche.br/site/br/arquivos/servicos/ biblioteca/digital/art18. pdf >. Acesso em: 18 set. 2012.

Ministério da Agricultura, Pecuária e Abastecimento - Assessoria de gestão estratégica: Brasil projeções do agronegócio 2010/2011 a 2020/2021. Brasília, junho de 2011. Disponível em:

<http://www.agricultura.gov.br/arq_editor/file/Ministerio/gestao/projecao/PROJECOES\%20 DO\%20AGRONEGOCIO\%202010-11\%20a\%202020-21\%20-\%202_0.pdf>. Acesso em: 09 set. 2012.

Ribeiro, W., C. 2008. "Aqüífero Guarani: gestão compartilhada e soberania”. Estudos avançados. v. 22, n.64. pp. 227-238.

SCHMITT, C. J. Sociedade, natureza e desenvolvimento sustentável: uma abordagem preliminar. Porto Alegre: PPGS/UFRGS, março 1995. (Datilog.)

SILVA, V AMARAL, A. M. P; ANEQUINI, F. R.; CAMARGO, F. P.; ANDRADE, J. P. S. Indicadores de Eficiência da Pequena Produção Leiteira na Região de Bauru, Estado de São Paulo. Instituto de Economia Agrícola. Grupo de pesquisa 7. Agricultura Familiar, 2003. p. 02. Disponível em : <http://www.iea.sp.gov.br/download/474-silva.pdf>. Acesso em: 09 set. 2012.

SILVA, M. C; BUENO, O. C. Análise Preliminar da Produção sustentável de leite bovino pela agricultura familiar no município de Torre de Pedra/SP. In: I WORKSHOP EM CIÉNCIAS AMBIENTAIS UNESP CAMPUS SOROCABA. VII Semana do Meio Ambiente - Sustentabilidade: Desafios e soluções, 2011, Sorocaba. Anais ... Soracaba, 2011. 1 CD-ROM.

SILVEIRA, J. T. Análise energética da produção de leite bovino na fazenda experimental professor Hamilton de Abreu Navarro - ICA/UFMG, em Montes Claros. Montes Claros, 2010. 132p. Dissertação (Mestrado em Ciências Agrárias) - Universidade Federal de Minas Gerais.

ZOCCAL, R.; CARNEIRO, A. V.; CARVALHO, G.; STOCK, L. A.; CHAIB FILHO, 11.; GARAGORRY, F. L. Distribuição espacial da pecuária leiteira no Brasil. In: REUNION LATINO AMERICANA DE PRODUCCION ANIMAL (ALPA), 20, Cuzco, Peru, 2007. Anais ... Cuzco, Peru, ALPA.

ZOCCAL, R.; ALVES, E. R.; GASQUES, J. G. Estudo Preliminar Contribuição para o Plano Pecuário 2012. Diagnóstico da Pecuária de Leite nacional, 2011. Disponível em: < http://www.cnpgl.embrapa.br/nova/Plano_Pecuario_2012.pdf>. Acesso em: 06 set. 2012. 